\title{
Encuentros y desencuentros en el conflicto Árabe-Israelí: el paradigma de la seguridad nacional
}

\author{
Agreements AND DisAgreEMENTS IN THE \\ Arab-IsRaeli CONFLICT: THE PARAdigm \\ OF NATIONAL SECURITY
}

Yaniza Giraldo Restrepo*

Resumen: La situación de conflicto que viven palestinos e israelíes continúa sin avances significativos para las partes a pesar del intento de la Comunidad Internacional por conseguir una paz duradera. En la región se han incrementado los fundamentalismos, los cuáles han llevado a un espiral de violencia y aumento del terrorismo en la región. No obstante, la protección y efectividad de los Derechos humanos sigue siendo parte fundamental y necesaria para conseguir acuerdos duraderos. El Estado de Israel puede tener un papel importante en el apoyo y protección de los Derechos humanos en la región, a través de la doctrina del Tribunal Supremo de Israel. Así que la respuesta no estará en los tradicionales paradigmas de las Relaciones Internacionales, sino que la solución debe ser fundamentado desde el Derecho y el reconocimiento de éste.

Palabras clave: Reconocimiento; Corte ocupación, Retorno, Palestina.

Abstract: The conflict Palestinians and Israelis living continues

* Yaniza Giraldo Restrepo: Doctora en Derecho de la Universidad Carlos III de Madrid. Máster en Derecho Público de la Universidad Carlos III de Madrid. Máster en Derecho Internacional y Relaciones Internacionales de la Universidad Complutense de Madrid. Abogada de la Universidad Libre de Cali. Docente de Tiempo Completo de la Universidad San Buenaventura de Cali. Facultad de Derecho y Ciencias Políticas. Derecho Internacional Público.

ygiraldo1@usbcali.edu.co without significant progress on the parties, and despite the attempts of the international community to achieve a lasting peace remains. In the region have increased fundamentalism, those which have led to an increasing spiral of violence and terrorism in the region. However, the safety and effectiveness of human rights remains essential and necessary for lasting agreements. The State of Israel can have an important role in the support and protection of human rights in the region, through the doctrine of the Supreme Court of Israel. So the answer is not in the traditional paradigms of international relations, but the solution should be based from the law and the recognition of it.

Keywords: Court; Recognition; occupation, Return, Palestine. 


\section{INTRODUCCIÓN}

El Estado de Israel se creó en 1948 meses después que la Asamblea General de las Naciones Unidas aprobara la Resolución 181 (II) en 1947 (Naciones Unidas, 1947), la cual determinaba la retirada del mandato británico, la retirada progresiva del ejército inglés, y la fijación de fronteras entre el Estado judío, el Estado palestino y Jerusalén (Izquierdo, 2003). El enfrentamiento armado entre ambos pueblos ha constituido una constante de odio e intolerancia en la historia del Oriente Medio durante los últimos sesenta y cinco años. Las opuestas reclamaciones de dominio territorial sostenidas por ambos pueblos sobre el territorio de Palestina, han conducido a un enfrentamiento permanente entre el Estado de Israel y el pueblo palestino.

En este conflicto se conjugan diversos factores que inciden en el mismo: surge a raíz de la disputa territorial entre los movimientos nacionales presentes en la región (Barrañeda, 2004, p.406) y el apoyo de las distintas potencias mundiales, lo que sin lugar a duda ha incrementado el conflicto. A esto se le suma la ideología religiosa, política, étnica, que dan paso al surgimiento cada día de nuevas reivindicaciones de ambas partes producto del conflicto permanente y de la ocupación por parte del Estado de Israel en los territorios palestinos ${ }^{1}$ (Aranda; Palma, 2006, p. 100).

Si bien, las causas anteriores propiciaron el conflicto y el odio entre los dos pueblos, una de las circunstancias que han deteriorado las relaciones y posibilidades de llegar a una paz duradera es la de los Territorios Ocupados. El Estado de Israel ocupó Cisjordania, Jerusalén Este y la Franja de Gaza en el año 1967, lo que le valió a Israel la condena de las Naciones Unidas en distintas ocasiones, a pesar de que esta no haya sido capaz de imponer sus resoluciones (Comisión de Derechos Humanos, 2001/15).

Ahora bien, pese a la ocupación no se debe olvidar que el pueblo palestino tiene derecho a la autodeterminación, a la autonomía y delimitación de su territorio. (Casañas, 2008, p. 144). El concepto de autodeterminación expresa entonces la capacidad que tiene cada pueblo o nación para crear el gobierno de acuerdo a sus necesidades, teniendo en cuenta su cultura y la manera como

\footnotetext{
1 Cuando se habla de Territorios Palestinos se hace referencia a Cisjordania, Jerusalén Este y la Franja de Gaza. A pesar de que el territorio de Gaza fue entregado de manera unilateral por el anterior ministro Ariel Sharon en el 2005, no obstante, de conformidad con la IV Convención de Ginebra de 1949, Titulo III artículo 27, no se puede decir que Gaza sea un territorio totalmente independiente y por esto, el trato de las personas protegidas debe seguir siendo el mismo otorgado a las personas bajo ocupación.
}

REVISTA DO DIREITO PÚBLICO, Londrina, v.9, n.1, p.121-134, jan./abr.2014 
llevará a cabo su política exterior (Payero, 2012, p. 209). El derecho de los pueblos es un derecho de humano fundamental que corresponde al Estado como también aquellas comunidades culturales que aspiren a su reconocimiento.

En este sentido, Ferrajoli (2006, p. 119) hace una conexión entre derechos e igualdad. La igualdad que se refleja en los derechos de libertad otorgados a todas las minorías, y la base del mismo que es la reducción de la desigualdad de las personas. Es decir, esto irá relacionado e intrínseco con el derecho fundamental que tienen los pueblos de vivir en paz (Ferrajoli, 2006, p. 119). Entonces, la paz significa que los pueblos puedan convivir de forma pacífica tomando como punto de partida la igualdad de los derechos y la libre determinación de los pueblos² . Algo que sin duda carece la población palestina al vivir bajo la ocupación porque no puede decidir por su desarrollo social, económico y cultural. La IV Convención de Ginebra de $1949^{3}$, permite a la potencia ocupante cambios en la región ocupada, no obstante, esto no tiene porque ser incompatible con la aplicación el Derecho Internacional de los Derechos Humanos en la aplicación y respeto del derecho fundamental del pueblo palestino de auto determinarse.

Sin embargo, no sólo la ocupación ha sido la causante de las crisis humanitarias que se presentan en palestina, sino que también ha contribuido la radicalización y falta de unidad del mismo pueblo palestino, las divisiones políticas que no permiten la consolidación de un proyecto de país para el mismo (De Faramiñan, 2009, p.3).

Otro de los factores que no permite que haya estabilidad en la región es el establecimiento del gobierno militar, figura permitida por el Derecho internacional que dispone la transferencia de la autoridad legislativa a la potencia ocupante (Rubinstein, 1988, p.72). El gobierno tiene la capacidad para dictar normas secundarias en materias de seguridad y delincuencia. El gobierno militar israelí ha tomado medidas de control con el fin de eliminar cualquier amenaza a la seguridad de la población israelí (Benvenisti, 1993, pp. 9-10). Estos cambios legislativos realizados después de la guerra de 1967 y la posterior ocupación de Cisjordania, Gaza y Jerusalén (Rodrigo, p. 301) han sido en materia política, económica, militare y gubernamentales (Vilanova, Pere. 1999, p. 17).

\footnotetext{
${ }^{2}$ Ibidem., p. 120.

${ }^{3}$ Véase Sección III, Territorios Ocupados.

${ }^{4}$ El Estado de Israel no reconoce la ocupación y manifiesta que los territorios están bajo administración. En este sentido, el Estado sólo ejerce las prerrogativas del poder público sin llegar a ostentar la soberanía de los mismos.
} 
Las disposiciones internacionales hablan de manera general sobre el establecimiento del gobierno militar, la IV Convención de Ginebra relativa a la Protección de Personas Civiles en tiempos de Guerra de 1949, pero no hace un análisis exhaustivo en cuanto a la aplicación y potestad que tiene el mismo de cambiar las condiciones tanto geográficas como jurídicas de la región. En esta misma línea, describe la posibilidad de extender en el tiempo estos poderes durante el transcurso de la ocupación

A su vez, el Derecho internacional no tiene una regulación expresa de las funciones que tendrá la autoridad militar en la región ocupada, sino que tan sólo prevé la responsabilidad que tiene el gobierno ocupante dentro de ésta (Benvenisti, 1993, pp. 9-10). Por consiguiente, la organización del gobierno militar será una función del Estado que ocupa la región (Singer, 1982, p.261) y por tanto, puede intervenir en todos los aspectos de la vida de la población ocupada.

En situaciones de ocupación prolongada se puede transformar la vida de la población de acuerdo con las disposiciones internacionales, y aunque no especifica qué hacer, sí otorga poderes legislativos a las autoridades ocupantes para decidir sobre la vida de la población. Todo esto de conformidad con el marco normativo de las Leyes de la Guerra que confieren poder al gobierno militar sobre la población ocupada (Cohen, 1985-1986, p. 479). La autonomía otorgada al gobierno militar no será ilimitada y por tanto, las actuaciones del mismo deben estar conforme a las leyes de ocupación beligerante que establecen los límites a su autoridad (Cohen, p. 480).

Ahora paso analizar los cambios establecidos por el gobierno militar respecto del retorno de los refugiados palestinos, los también llamados palestinos de 1948 (Camargo, J. Jesús, 2008, p. 14) y que sin duda constituye uno de los temas de negociación.

\section{EI RETORNO DE LOS PALESTINOS DE 1948}

El problema del éxodo palestino se originó fundamentalmente en los desplazamientos de población motivados por la ocupación israelí durante las guerras de 1948 y de 1967 (Guerra de los Seis Díaz). Estos se encuentran dispersos entre la Franja Gaza, Cisjordania, Líbano, Siria y Jordania (Barrañeda, 2005, p. 136).

En el territorio de Israel permanecieron alrededor de 100.000 palestinos, que aceptaron el nuevo Estado y se convirtieron en ciudadanos israelíes, pasando este grupo a ser una minoría árabe dentro del Estado judío (Mac Liman, 1995, 
p. 9) el resto de la población que no pudo demostrar su residencia en la región, tuvo que abandonar la región y refugiarse en otros países.

Entonces, después de la creación del Estado de Israel han aumentado las causas del conflicto entre palestinos e israelíes, lo que ha llevado a la región a un espiral de violencia. El Estado de Israel se ha visto abocado a luchar con el creciente número de grupos terroristas que aprovechan la ocupación para llevar a cabo sus objetivos terroristas y que nada tienen que ver con la lucha del pueblo palestino por su independencia. Para hacer frente a los ataques de los grupos terroristas, el Estado ha tomado una serie de medidas legales y cambios normativos que permitan hacer frente a las amenazas terroristas. Entre otros, se observa las detenciones administrativas en aras de controlar y mantener la seguridad nacional.

\section{DERECHOS HUMANOS Y DETENCIONES ADMINIS- TRATIVAS}

El Estado de Israel tiene dentro de su política las detenciones administrativas como una medida para luchar contra el terrorismo y un mecanismo para preservar la población. Esta práctica ha sido denominada como: Doctrina de la Seguridad Nacional. En este caso, el Estado goza de autoridad ilimitada y por ello, no es posible hablar de una ley superior moralmente obligatoria que proteja los derechos fundamentales de los detenidos. Esto sin duda ha traído consigo la tiranía del Estado frente a la población ocupada. (Rivas, 2008, p. 48).

La normativa internacional permite las detenciones como una medida administrativa como forma de control y mantenimiento de la paz en la región ocupada ${ }^{5}$. En este sentido, la ley de procedimiento penal israelí admite la detención de sospechosos por un máximo de 96 horas antes de comparecer ante un juez por delitos contra la seguridad (Comité Contra la Tortura, 2009, párr. 15). Las garantías jurídicas que se otorguen a los detenidos son necesarias para el cumplimiento del debido proceso y la protección frente a los malos tratos y torturas.

Ahora bien, este método despótico de detenciones genera inseguridad jurídica porque los detenidos prefieren negociar los cargos penales así no hayan participado dentro de ninguna actividad terrorista antes que estar privados de su libertad por mucho tiempo. El caso de los detenidos palestinos es que estos en la negociación de los cargos penales aceptan la responsabilidad de los actos

\footnotetext{
${ }^{5}$ Artículos 41, 42, IV Convenio de Ginebra de 1949.
} 
y reciben una reducción de la pena (B’tselem, 1990, p.13). De manera que la aceptación no siempre es voluntaria sino como una forma de dar por terminada su detención, porque no se les otorga la libertad bajo fianza porque la gran mayoría son acusados de ofensa criminales (B’tselem, 1990, p.13; Peleg, 1995, p.96).

El caso de la detenciones administrativas se puede interpretar desde la teoría del Derecho penal del enemigo, que consiste en tratar a la parte contraria como un enemigo y por tanto, todas las prácticas represivas son justificadas, desconociendo todo el debido proceso y la protección de los derechos humanos de los mismos(Ambos, Kai. 2007, p. 90). En este sentido, el gobierno de Israel considera que por motivos de seguridad y en prevención de posibles atentados terroristas es necesaria la detención de personas sospechosas, para la protección de la población (Ambos, Kai, 2007, p. 92).

En situaciones complejas como las que vive el Estado de Israel frente a la lucha contra el terrorismo y la protección de los derechos fundamentales, se debe tener en cuenta la teoría de la ponderación. Ésta ha sido denominada por Alexy (2002) “el margen para la elección de medios” cuando las normas de derechos fundamentales prohíben algunas transformaciones legislativas y a su vez, establecen la realización de algunas conductas positiva cuando están en medio el deber de proteger (Alexy, 2002, p. 25). Ahora bien, esta regla no se cumple cuando para alcanzar un objetivo, en este caso la lucha contra el terrorismo y la protección de la población israelí, se utilizan prácticas que violan los derechos fundamentales de los sospechosos de pertenecer a grupos criminales, pero que sirven para evitar la muerte de la población civil israelí.

Lo anterior va en contra de la Teoría de los Derechos Fundamentales la cuál dispone que una acción se realice de la mejor y dependiendo de las posibilidades jurídicas y fácticas (Alexy, 2002, p. 25). En este caso es preciso analizar las diferentes practicas para cumplir con este fin, y hacer una ponderación de las mismas para considerar las posibilidades que existen y los medios que pueden perjudicar o favorecer aquellos principios que entran en juego. En este caso, se tendrá un margen de ponderación donde las medidas tomadas sean necesarias e idóneas, por consiguiente, proporcionales (Alexy, 2002, p. 26).

La interpretación del Derecho internacional por parte del Estado de Israel y los cambios legislativos realizados en la región ocupada, han sido cuestionados por la Comunidad Internacional porque violan los derechos fundamentales de la población, y crean un doble sistema jurídico, uno para el gobierno ocupante y otra para la población bajo ocupación. Pero no se corresponden con las 
obligaciones del derecho internacional y la obligación de la potencia ocupante de proteger a la población protegida.

Es decir, el Estado de Israel ha creado una nueva legislación que desconoce los derechos de la población bajo ocupación, y por tanto, no permite la autodeterminación de la población palestina. Por tanto, estos cambios establecidos en palestina han desconocido las normas internacionales aplicables en casos de ocupación y han ocasionado un obstáculo para alcanzar la paz.

\section{GOBIERNO MILITAR EN LOS TERRITORIOS OCUPADOS}

Los cambios legislativos realizados por el gobierno militar en un territorio ocupado son permitidos de acuerdo con el Derecho internacional y no existe la prohibición de cambiar las normas punitivas que se encuentren en el momento de la ocupación beligerante. Estos cambios se pueden realizar sólo si es necesario para mantener la seguridad del territorio bajo ocupación ${ }^{6}$. En el caso del conflicto palestino, los tribunales locales revisan la legalidad y la validez de los actos administrativos conforme a la costumbre internacional. En lo que respecta a los oficiales israelíes, éstos tienen en cuenta la aplicación de las normas administrativas de acuerdo a cada situación que se presente (Shamgar, 1971, p. 47).

El cambio o suspensión del derecho o promulgación de nuevas leyes estará acorde con las restricciones prescritas en el artículo 64 de la IV Convención de Ginebra y el artículo 43 de las Reglamentos de la Haya. Los tribunales Palestinos tienen jurisdicción territorial para llevar los casos penales de ciudadanos israelíes residentes en los territorios ocupados. No existe una ley u orden militar que estipule que un ciudadano israelí no puede ser juzgado ante un tribunal local en cuestiones penales (Peleg, 1995, p. 76). Sin embargo, esto no se lleva a la práctica porque los colonos judíos no están dispuestos a ser juzgados por un tribunal palestino

El primer parágrafo del Artículo 64 de la IV Convención de Ginebra establece dos tipos de excepción al cambio de las leyes en vigor en el momento de la ocupación: la amenaza a la seguridad del ocupante y el obstáculo para aplicar la Convención. Debe existir el compromiso de modificar la normativa para mantener el orden y asegurar la seguridad del ocupante, pero siempre dentro de un sistema legal acorde con los principios y poderes otorgados jurídicamente. Por consiguiente, los poderes del ocupante están limitados para

${ }^{6}$ Artículo 64 de la IV Convención de Ginebra de 1949. Artículo 43 del Reglamento de la Haya de 1907, relativo a las leyes y costumbres de la guerra terrestre.

REVISTA DO DIREITO PÚBLICO, Londrina, v.9, n.1, p.121-134, jan./abr.2014 
introducir una legislación en nombre de la seguridad que sean contrarios a la IV Convención de Ginebra y los Reglamentos de la Haya. Como podría ser la promulgación de leyes penales que sancionen los delitos cometidos por la población civil ocupada y no estén codificados en la IV Convención de Ginebra.

El Estado de Israel cumple con las condiciones de un "Estado de Derecho" en donde los poderes públicos se rigen por la ley y actúan de conformidad con lo establecido por la misma. No obstante, la ley limita la actuación de los poderes públicos porque están supeditados al cumplimiento de las normas constitucionales y a la protección de los derechos fundamentales (Ferrajoli, 2002, p. 187). Por tanto, frente al conflicto, las instituciones del Estado de Israel deben crear las condiciones de existencia y validez de las normas jurídicas, no sólo dentro del Estado, sino también en los territorios ocupados. Toda vez que se debe tener como punto de partida el principio de legalidad a manera de garantía frente a todas las posibles arbitrariedades que se puedan cometer contra la población bajo ocupación (Ferrajoli, 2002, p. 187).

No obstante, entre la normativa de los derechos humanos y su cumplimiento hay una gran brecha, porque no se tienen en cuenta de la misma manera los derechos de la población palestina bajo ocupación. El Tribunal Supremo de Israel (en adelante TSI) siguió dos conceptos básicos dentro de su doctrina: el Estado de Israel como una democracia moderna y la protección de los derechos humanos como algo fundamental dentro del Estado. El TSI ha reconocido que el Estado no está aislado porque hace de una Comunidad Internacional, por ende, tiene obligaciones que lo vinculan internacionalmente (Higgins, 1997, p. 37).

En consecuencia, las políticas y normas aplicadas en los territorios ocupados son diferentes a las disposiciones internacionales en materia de derecho de ocupación beligerante. Así que La protección de los derechos humanos en Israel es muy diferente a la aplicada dentro de los Territorios Ocupados. Es decir, el derecho israelí en este sentido no se aplica a estos, con excepción del Este de Jerusalén y los Altos del Golán. El derecho que se aplica en los territorios es el de ocupación beligerante. En situaciones de intervención militar, no importa el tipo de ocupación que sea, parcial, temporal, permanente, es necesario hacer una ponderación entre las leyes de ocupación beligerante y el derecho internacional de los derechos humanos aplicado en momentos de paz (Roberts, 2006, p. 619).

Entonces, no se debe aplicar sólo el derecho de la guerra porque si es así, se desconocerían todos los derechos de la población sometida a un gobierno militar. Es decir, la guerra y la ocupación no son prohibidas por el derecho 
internacional, por el contrario, son aceptadas y reguladas. De manera que se debe buscar un balance entre ambos instrumentos jurídicos para preservar los derechos de la población civil (Roberts, 2006, p. 619). Con la eficacia del derecho internacional dentro de los Territorios ocupados se limita el poder que tiene el gobierno militar sobre la población.

Es una práctica cada vez más frecuente el reconocimiento de las normas de derechos humanos en situaciones de ocupación, como también en condiciones parecidas a una ocupación militar. Como ejemplo se puede citar el caso de Gaza que sin ser ahora un territorio ocupado tiene características del mismo, pero que es distinto de los casos clásicos de ocupación. La aplicación de las normas de derechos humanos no es sencilla, presenta dificultades, pero proporciona herramientas y oportunidades importantes a los habitantes que se encuentran en el poder de las fuerzas externas (Roberts, 2006, p. 620).

Después de la ocupación de 1967 el derecho internacional toma relevancia dentro de la jurisprudencia israelí. El TSI hace una interpretación de las disposiciones internacionales, los principios del derecho público de Israel, así como el derecho vigente previo a la ocupación.

El TSI en algunas ocasiones en su jurisprudencia se aparta de la doctrina del Poder Ejecutivo, que dan prioridad a la seguridad sobre los intereses de la población ocupada. A su vez, han otorgado la posibilidad de suspender la aplicación de los tratados en materia de derechos humanos, por su difícil cumplimiento en situaciones de conflicto. Éste hace un balance entre la normativa interna y la internacional. El TSI aplica el derecho internacional en sus decisiones respecto al conflicto palestino-israelí, siempre desde la base del derecho internacional de la ocupación beligerante y la aplicación de la costumbre internacional.

El TSI ha hecho una ponderación entre la posición del gobierno frente a los Territorios Ocupados y las necesidades de la población civil bajo ocupación. En su doctrina ha respondido a las preguntas relacionadas con la obligación de cumplir con los tratados internacionales, las controversias respecto a la aplicación de la normativa vigente en el momento de la ocupación y su competencia más allá de las fronteras de Israel (Lapidoth, 1990, p. 451).

A pesar de lo anterior, aunque los derechos humanos son primariamente designados para tiempos de paz, la potencia ocupante en este caso Israel, está en la obligación de cumplir con estos tal como lo ha venido mostrando la practica internacional de los derechos humanos, controlado por los diferentes organismos internacionales como: la Corte Internacional de Justicia (Distein, 2009 p. 69) y las Naciones Unidas a través de sus diferentes procedimientos públicos. En 
consecuencia, si no se aplica dentro de los Territorios Ocupados el derecho internacional de los derechos humanos constituiría un incumplimiento de las disposiciones internacionales y los tratados internacionales vinculantes para el Estado de Israel.

Ahora bien, los Estados se comprometen a través de tratados internacionales a cumplir con obligaciones. No obstante, esta regla no aplica para aquellos Estados que se encuentran en conflicto siempre y cuando exista una excepción permitida para la suspensión de los derechos. Por tanto, el derecho interno debe estar en consonancia con las disposiciones internacionales. Esto es algo que sin duda no ha podido ser explicado de manera clara por el gobierno de Israel ante la política de los asentamientos judíos y la transformación de las fronteras territoriales establecidas antes de 1967. Por consiguiente, le ha restado confiabilidad internacional y legitimidad al Estado de Israel por llevar a cabo una política expansionista.

\section{ASENTAMIENTOS JUDÍOS}

El tema de adquisición de tierras ha sido una de las modificaciones que ha hecho el gobierno militar. La autoridad municipal encargada de la planificación de la tierra fue reducida y prohibió la construcción y ubicación de viviendas incluso dentro o fuera de los límites municipales de cualquier ciudad palestina.

Esto ha permitido la expansión y creación de asentamientos israelíes en lugares donde reside la población palestina (Farramiñan, 2009, p. 7). Las órdenes de planificación territorial han otorgado al Gobierno israelí tener más facilidades para continuar con su política de asentamientos ilegales, contribuyendo al subdesarrollo de la región. La falta de delimitación de fronteras en territorios palestinos, hace que sea aún más incierto la posible resolución del conflicto y la paz duradera en la región.

Los cambios realizados en la región Palestina por parte del Gobierno Militar han sido justificados como necesarios para mejorar las condiciones de la población palestina. Esta posición ha sido analizada por la doctrina del TSI argumentando que los asentamientos civiles tanto del pasado como el presente no constituyen un motivo válido para las Fuerzas de Defensa de Israel como forma de proteger la seguridad nacional (Barguil v. Government of Israel, 1991, p. 4).

Además, la acción de la administración militar debe ser tomada como algo transitorio que termina al finalizar la ocupación. Empero, las facultades que tiene el Gobierno Militar en la región para restablecer la ley y el orden, no 
otorgan derechos para la construcción de nuevos asentamientos o la expulsión de la población palestina de la región. Es decir, en el momento de establecer los asentamientos de manera permanente, genera un cambio que no se toma como medida transitoria y que por el contrario, agrava más la situación de conflicto en la región.

\section{CONSIDERACIONES FINALES}

Es necesario aplicar el Derecho Internacional Humanitario y el Derecho Internacional de los Derechos Humanos en los Territorios Ocupados, porque las disposiciones del derecho de ocupación beligerante no siempre responden a las situaciones que suceden dentro de una ocupación militar prolongada. No obstante, dadas las condiciones de la región y el cambio legislativo en estos años de ocupación, serán siempre provisionales y no a favor del Estado ocupante.

Aunque la jurisprudencia del TSI ha contribuido a la protección de los derechos fundamentales, creando una cultura de los derechos humanos, no se puede decir que haya seguido la misma política cuando se trata de los derechos civiles de la población árabe-israelí, ni de los Territorios Ocupados. Por consiguiente, para lograr un acuerdo duradero de paz en la región, es necesario que se respete y valide el derecho internacional, partiendo del reconocimiento de ambos pueblos al derecho a vivir en paz. Como también, del derecho fundamental que tiene la población palestina de autodeterminación. Esto incluye todas las organizaciones políticas de la Autoridad Nacional Palestina como del gobierno de Hamás. Esto puede contribuir a consolidar la democracia en la región, y la lucha contra el terrorismo.

Por otra parte, los compromisos deben ser apoyados por el Estado de Israel quien deberá comprometerse a la retirada efectiva de las fuerzas militares, el reconocimiento del Estado Palestino y la retirada de los asentamientos judíos que condicionan los futuros acuerdos de paz. Las negociaciones y acuerdos de Paz logrados por las partes no tendrán efectividad sino están respaldadas por la población de ambos pueblos, el reconocimiento de los derechos fundamentales de ambos pueblos.

\section{REFERENCIAS}

ALEXY, Robert. Epílogo a la teoría de los derechos fundamentales. Revista Española de Derecho Constitucional. Año 22. Núm. 66. SeptiembreDiciembre, 2002. 
ARANDA, Gilberto; PALMA, Luis. Oriente Medio, una eterna encrucijada. Santiago: Ril Editores, 2006.

BARRAÑEDA BAJO, Isaías. Identidad nacional y ciudadanía en el conflicto israelopalestino. Los Palestinos con ciudadanía israelí, parte del conflicto y excluidos del proceso de Paz. Tesis de Doctorado, Universidad Complutense de Madrid, 2004. Recuperado de http:// eprints.ucm.es/5432/1/ucm-t28073.pdf

BENVENISTI, Eyal. The international law of occupation. New Jersey: Princeton: Universal Press, 1993.

B'Tselem. The Military Judicial System in the West Bank- Followup Report. May 1990, p. 13. Disponible en: http://www.btselem.org/ publications?date_filter\%5Bvalue\%5D\%5Byear \%5D=1990\&tid=All

CAMARGO, J. Jesús. Edward W. Said: 60 años después de la Naqbah y la negación de la ciudadanía a los refugiados palestinos. Astrolabio. Revista internacional de filosofía. Núm. 7, 2008. ISSN 1699-7549.

CASAÑAS, Joan, ed. La autodeterminación de los pueblos. Barcelona: Icaria, 1 edición, 2008.

COHEN, Esther Rosalind. Justice for Occupied Territory? The Israeli High Court of Justice Paradigm. Colum. J. Transnat'1 L. Vol. 24, 1985-1986,

DE FARAMIÑAN, Gilbert, Juan Manuel. El conflicto palestino-israelí (una perspectiva desde el Derecho internacional y los modelos de solución de conflictos, Revista de Estudios Jurídicos. Núm.9, 2009.

\section{DISTEIN, Yoram. The International Law of Belligerent Occupation.}

Cambridge: University Press, 2009.

FERRAJOLI, Luigi. Sobre los derechos fundamentales. Cuestiones Constitucionales. Núm. 15, julio-diciembre, 2006.

FERRAJOLI, Luigi. Pasado y futuro del Estado de Derecho. En, CARBONEL, Miguel; OROZCO, Wistano; VÁZQUEZ, Rodolfo (coords.). 
Estado de Derecho: concepto, fundamentos y democratización en América Latina. México: Siglo Veintiuno, primera edición, 2002.

HIGGINS, Rosalyn. The Role of Domestic Courts in the Enforcement of International Human Rights: The United Kingdom. En CONFORTI, Benedetto, FRANCIONE, Francesco. Enforcing International Human Rights in Domestic Courts. The Hague: Kluwer Law International, 1997.

IZQUIERO BRICHS, Ferrán. El movimiento sionista ante la partición de Palestina. Barcelona: Scripta Nova. Vol. VII. Núm. 144, 1 de julio, 2003.

KAI, Ambos. El derecho penal frente amenazas extremas. Madrid: Dykinson, 2007.

LEY BÁSICA: Jerusalén, Capital de Israel. 30 de julio de 1980. Disponible en http://www.mfa.gov.il/MFA/MFAArchive/1980_1989/Basic+Law+ Jerusalem+Capital+of+Israel.htm

LAPIDOTH, Ruth. International Law within the Israel Legal System. Israel Law Review. Vol. 24, 1990.

MAC LIMAN, Adrián. Palestina: De la nación de refugiados al Estado Nación. Madrid: Popular, 1995.

NACIONES UNIDAS. Futuro Gobierno de Palestina. 29 de Noviembre de 1947. Disponible en: http://www.un.org/spanish/documents/ga/res/2/ ares2.htm

PAYERO LÓPEZ, Lucia. El triunfo de la ley del más fuerte: la concepción ferrajoliana del derecho de autodeterminación de los pueblos. Cuadernos Electrónicos de Filosofía del Derecho. Núm. 26, 2012.

PELEG, Ilan. Human rights in the West Bank and Gaza: Legacy and Politics. New York: Syracuse University Univ. Press, 1995.

ROBERTS, Adam. Transformative Military Occupation: Applying the Laws of Ward and Human Rights. The American Journal International Law. Vol. 100, 2006. 
RODRRIGO HERNÁNDEZ, Ángel J. Soberanía y administración de territorios. Anuario Español de Derecho Internacional. Vol. XX, 2004.

RIVAS NIETO, Pedro. Doctrina de Seguridad Nacional y Regímenes Militares en Iberoamérica. Alicante, Ecu, 2008.

RUBISTEIN, Amnon (1988). 'The changing status of the "territories" (West Bank and Gaza): From scrow to legal mongrel'. Tel Aviv University Studies in Law. Vol. 8, 1998.

SHAMGAR, Meir. Legal Concepts and Problems of the Israeli Military Government-The Initial Stage, Israel Yearbook on Human Rights. Vol. 1, 1971.

VILANOBA, Pere. Jerusalén: el proceso de paz en Oriente Medio. Barcelona: Icaria, 1999.

Sentencias y Resoluciones de Naciones Unidas

ASAMBLEA GENERAL, Resolución, 32/20 noviembre 25 de 1977. CAT/C/ISR/CO/4, 23 de junio de 2009, párr. (15). Disponible en: http:// www2.ohchr.org/spanish/bodies/cat/

COMISIÓN DE DERECHOS HUMANOS. Situación en los territorios palestinos y otros territorios árabes ocupados por Israel, 2001/15.

HCJ 4481/91, Barguil v. Government of Israel, p. 4. Recuperado dehttp:// elyon1.court.gov.il/files_eng/91/810/044/Z01/91044810.z01.pdf

Artigo recebido em: 17/12/2013 Aprovado para publicação em: 01/04/2014

Como citar: RESTREPO, Yaniza Giraldo. Encuentros y desencuentros en el conflicto Árabe-Israelí: el paradigma de la seguridad nacional. Revista do Direito Público. Londrina, v.9, n.1, p.121-134, jan./abr.2014. DOI: 10.5433/ 1980-511X.2014v9n1p121. 